\title{
Application of an analog downscaling technique to the assessment of future landslide activity - a case study in the Italian Alps
}

\author{
Martin Dehn* \\ Department of G eography, University of Bonn, Meckenheimer Allee 166, 53115 Bonn, G ermany
}

\begin{abstract}
Slope stability and hence landslide activity is in many cases related to climate, which influences groundwater and pore pressure fluctuations of hillslopes. An approach is presented which transforms transient GCM output by statistical downscaling to local precipitation scenarios, which together with directly derived temperature scenarios are subsequently fed into a slope hydrological/stability model to derive future landslide activity. This model chain is applied to a landslide in the Dolomites, Italy. Validation of the approach against independent observed records suggests its applicability for estimating future landslide activity based on GCM results. One possible way of estimating the quality of the approach is to determine sources of uncertainty introduced by the GCM simulations and by different fitting periods of the downscaling technique. Differences between the GCM experiments are found to be more important than differences between the 2 fitting periods. The most striking result is the significant reduction of landslide activity in spring in all cases. This is attributable to the rise of winter temperature which impedes future storage of winter precipitation as snow. As one consequence, less melt water is available for the hillslope in spring, causing the decrease in activity. It can be concluded that differences between GCMs and differences between fitting periods permit quantification of part of the uncertainty inherent in climate change impact assessments. Impacts which emerge in all model combinations, such as the decrease in landslide activity in spring shown here, have a high level of confidence.
\end{abstract}

KEY WORDS: Landslide activity $\cdot$ Climate change $\cdot$ GCM $\cdot$ Downscaling

\section{INTRODUCTION}

Landslides are a common feature of mountainous regions around the world. Depending on location and time of occurrence, these landslides can be a threat to society, and have caused large numbers of casualities and huge economic losses. They are mainly triggered by climate and seismic activity: rainfall-triggered landslides are the most common (Crozier 1986, Gostelow 1991).

The fact that climate is a boundary condition of landslide activity explains the interest of landslide research in climate change projections for the next century. The wide range of landslide types (Dikau et al. 1996) requires separate investigations for each type of setting.

*E-mail: martin.dehn@giub.uni-bonn.de
The case of a mudslide in the Dolomites, Italy, reaching a small village is presented here. The local population and authorities are alarmed at the possibility of future disastrous collapse-like activity of the mudslide, which could damage a residential area and a road. Three research strategies were developed in order to gain some insight in the future development of the landslide: (1) monitoring of slope movement and groundwater behaviour; (2) development and application of hydrological and slope stability models which are able to reproduce the displacement features of the mudslide; and (3) application of a combined modelling approach linking slope hydrological/stability modelling with projections of global warming due to the enhanced greenhouse effect. The latter is the topic of the present paper. Large-scale projections of global warming are derived from general circulation models (GCMs), which at present provide the physically most plausible 
scenarios for possible future climates (Carter et al. 1996, Trenberth 1997). Due to the low horizontal resolution of GCMs, however, their results have to be postprocessed with downscaling techniques to derive local climate scenarios (von Storch 1995). Downscaling methods relate large-scale atmospheric features with local features such as station precipitation (see Hewitson \& Crane 1996, Zorita \& von Storch 1998). Subsequently, slope hydrological/stability models are forced with the local scenarios of climate change and return future scenarios of groundwater fluctuations and landslide activity. This approach was adapted for models and parameters of the present study and is shown in Fig. 1. It is clear that such a model chain facing future conditions is prone to various sources of error and therefore the results contain a considerable amount of uncertainty. This uncertainty of climate change impact scenarios impairs their presentation to those concerned as well as to policy makers. In the present study, attempts are made to quantify part of the uncertainty.

\section{LOCATION OF STUDY SITE}

The mudslide Alvera is located near Cortina d'Ampezzo in the Eastern Dolomites (Fig. 2). The mudslide is about $1700 \mathrm{~m}$ long and $100 \mathrm{~m}$ wide, extends from 1320 to $1520 \mathrm{~m}$ of altitude, and consists mainly of clayey material. In its lower reach it threatens a residential area, where a protective wall has been built as a countermeasure. The monitoring equipment con-

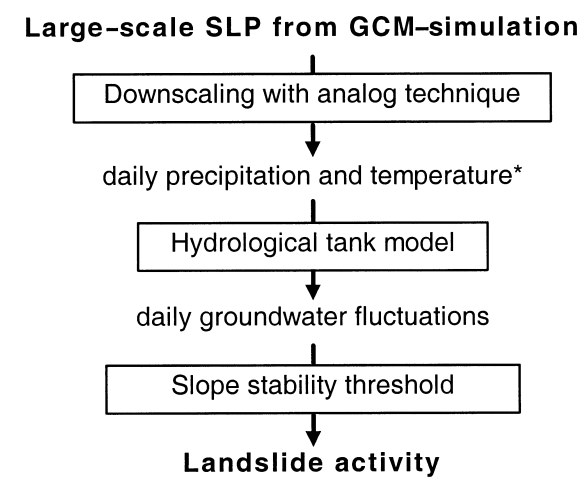

Fig. 1. Model chain applied for the assessment of landslide activity of Alvera mudslide. SLP: sea level pressure. *Temperature is not actually downscaled but derived directly from GCM grid points and calibrated with observations nected to an automatic recording system consists of inclinometric tubes and extensometers for measurement of landslide displacement, and piezometers for the observation of groundwater fluctuations. Sliding surfaces have been found at $5 \mathrm{~m}$ and $20 \mathrm{~m}$ depth (Angeli et al. 1998).

Observed precipitation records from the Meteorological Survey of Venice are available for Cortina d'A mpezzo (1922 to 1996), M isurina (1922 to 1975) and San Vito (1922 to 1987). M isurina is located $10 \mathrm{~km}$ ENE and San Vito $12 \mathrm{~km}$ SE of Cortina d'A mpezzo. The data of Cortina were tested for homogeneity against the other 2 stations considering daily and monthly precipitation totals, number of days with precipitation, and intraseasonal variability of daily precipitation. No obvious inhomogeneity in the series could be found. Daily air temperature is available from the same source for Cortina only, covering the period 1955 to 1985.

\section{IMPACT MODEL AND DOWNSCALING TECHNIQUE}

In order to simulate the behaviour of the Alvera mudslide a conceptual hydrological model and a slope stability model were developed and calibrated (Angeli et al. 1996, 1998). Together they are called the impact model in the following. 
Observed groundwater fluctuations of the mudslide indicate flow velocities which cannot be explained by the low permeability of the clayey matrix of the landslide body. Therefore preferential flow in macropores is suspected to be an important hydrological process operating in the landslide. The groundwater records suggest subdivision with a macroporous root zone, underlain by a less permeable stiff clayey layer which contains various dead-end cracks. The adapted hydrological tank model consists of 2 linear reservoirs placed in series which represent the 2 layers of the mudslide (Angeli et al. 1998). The lower tank (clayey layer) influences the upper tank (macroporous root zone) only when the former is filled with water. Water input is by precipitation only. Output occurs at the outlets of the tanks. No lateral transport is allowed in the model.

Input variables for the tank model are daily precipitation and air temperature. Temperature is used for the calculation of evapotranspiration and snow storage/ melt. Evapotranspiration is mapped very simply. For days with mean temperature $\leq 9^{\circ} \mathrm{C}$ evapotranspiration is neglected. For days with mean temperature $>9^{\circ} \mathrm{C}$ evapotranspiration is set to the fixed amount of $2.5 \mathrm{~mm}$ $\mathrm{d}^{-1}$. Snow storage and snow melt are also represented in a conceptual manner using a temperature-index model (Bergström 1976). Precipitation on days with mean temperature $<0^{\circ} \mathrm{C}$ is stored as snow. This storage is released at a temperature-dependent rate as melt water. The temperature-index model uses the term $\xi\left(T-T_{0}\right)$, with $\mathrm{T}=$ mean daily temperature $\left({ }^{\circ} \mathrm{C}\right), \mathrm{T}_{0}=$ threshold temperature for snow melt $\left({ }^{\circ} \mathrm{C}\right)$ and $\xi=$ snow melt rate $\left(\mathrm{mm} \mathrm{d}^{-1}{ }^{\circ} \mathrm{C}^{-1}\right) . \mathrm{T}_{0}$ and $\xi$ have to be empirically fitted to the model. The values $\xi=1.25 \mathrm{~mm} \mathrm{~d}^{-1}{ }^{\circ} \mathrm{C}^{-1}$ and
$\mathrm{T}_{0}=-1^{\circ} \mathrm{C}$ were used in the study (Buma 1998). An example of the performance of the tank model is presented in Fig. 3.

Slope stability and displacement rate are assessed through the application of a visco-plastic rheological model which is linked to groundwater fluctuations reflecting porewater pressure (Angeli et al. 1996, Gasparetto et al. 1996). Instead of applying the complete rheological model to derive daily rates of landslide displacement, the following simplified alternative was chosen in the present approach. The onset of displacement in the slope stability model is triggered when groundwater exceeds a critical level. In the case of the Alvera mudslide an infinite slope stability analysis revealed a critical threshold of $-0.5 \mathrm{~m}$ below the ground surface (Buma 1998). Hence the number of days with supercritical groundwater levels per time unit is an indicator of landslide activity, without information about magnitude. The number of days $>-0.5 \mathrm{~m}$ groundwater, on the other hand, yields sufficient information for the purpose of this study. The effect of soil strength regain, which is mapped in the slope stability model by the use of 2 stability thresholds, is neglected due to the fact that it had hardly any effect on the results of landslide activity fitted with data of Borehole S5 for the period 1990 to 1996. The overall performance of the combined hillslope hydrology/stability model was demonstrated in Angeli et al. (1998) with promising results.

The impact model requires local climate information at daily time steps, which can be provided by a downscaling technique based on daily GCM data. For precipitation an analog technique described in Cubasch et

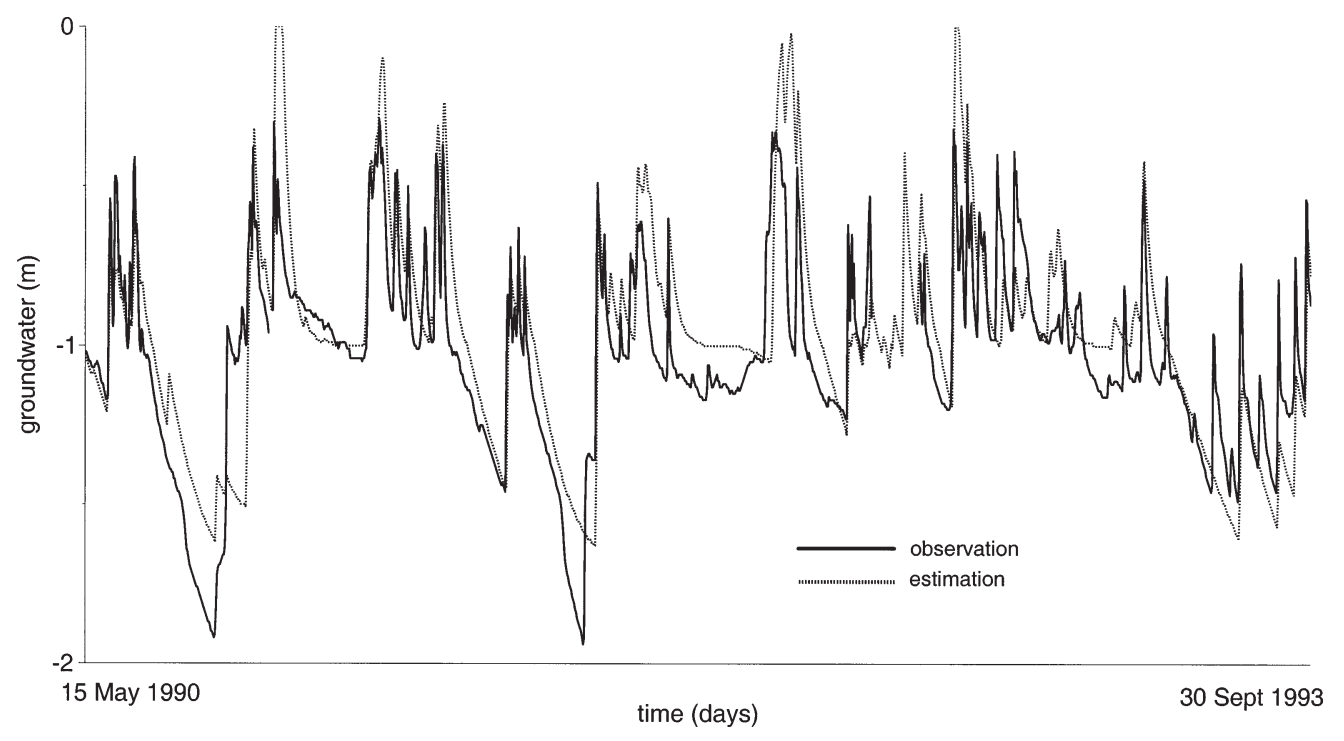

Fig. 3. Daily groundwater measured in Borehole S5 of Alvera mudslide (observation) and groundwater estimation with the tank model described in the text (estimation) for the period 15 M ay 1990 to 30 September 1993 
al. (1996) and Zorita \& von Storch (1998) was applied, relating large-scale atmospheric circulation represented by sea level pressure (SLP) fields and precipitation at Cortina. In this analog technique simultaneous observed SLP and precipitation for the fitting period are stored in a catalog. In the next step an independent set of SLP fields, e.g. another observed period or GCM output, is analysed with the objective of finding the most similar large-scale atmospheric situation in the catalog for each day of the target period. The most similar pattern is then called the analog, and the simultaneously observed precipitation amount is assigned the estimated precipitation of the respective day. In order to reduce the degrees of freedom and to filter out noise, the SLP field is projected onto its empirical orthogonal functions (EOFs) prior to the whole procedure. Pattern similarity is then determined with a nearest neighbour method.

In the present study the analog technique was carried out separately for the seasons March-A pril-May (MAM ), J une-J uly-A ugust (J A), September-OctoberNovember (SON) and December-J anuary-February (DJ F). The technique uses the first 5 EOFs of SLP and was run with a time lag of up to $2 \mathrm{~d}$. This means that the precipitation of Day $t$ is related to SLP of Days $t$, $\mathrm{t}-1, \mathrm{t}-2$. Rather than basing the similarity on a $1 \mathrm{~d}$ situation only, this takes into consideration the development of the atmospheric situation. The analysed SLP field covers part of the North Atlantic and Europe within the coordinates $70^{\circ} \mathrm{W}$ to $20^{\circ} \mathrm{E}$ and $20^{\circ}$ to $70^{\circ} \mathrm{N}$. SLP data from the NMC analyses (former National $M$ eteorological Center, now National Center for Environmental Prediction, NCEP) interpolated onto a $5^{\circ} \times$ $5^{\circ}$ grid was supplied by the US National Center for A tmospheric Research (NCAR) (Trenberth \& Paolino 1980).

For validating the technique the available record of observations has to be divided into independent fitting and target periods. The analog model is trained with the fitting period and is then applied to observed SLP of the target period to derive a reconstruction of the precipitation for the target period. When estimated and observed precipitation of the target period coincide the downscaling model can be applied to GCM output with the usual assumption that the empirically based relationship between SLP and local precipitation is stationary under climate change (see Buma \& Dehn 1998). One possible way, to test the stationarity of the method is to use 2 empirical analog models, each consisting of a fitting and a target period. The first consists of the fitting period 1962-91, used for the reconstruction of the period 1922-61. The second fitting period is 1946-75, which is applied for the reconstruction of the periods 1922-44 and 1976-94. In the following Analog 1 denominates the model based on fit- ting period 1962-91, and A nalog 2 the model based on the fitting period 1946-75. Validation parameters are time series correlations between observation and reconstruction of seasonal precipitation sums, intraseasonal variability represented by standard deviation of daily precipitation (high-frequency variability) and number of days per season with precipitation $>0.2 \mathrm{~mm}$ (Table 1). The threshold $0.2 \mathrm{~mm}$ discriminates between moist and dry days. This is somewhat arbitrary, but well within the range of various definitions ( 0.1 to $0.25 \mathrm{~mm}$ ) cited e.g. in Crowe (1971). Two further parameters are the 0.9 quantiles of daily precipitation $\left(q_{0.9}\right)$ and the low-frequency variability calculated as the standard deviation of seasonal precipitation (Table 2).

It is obvious that autumn and winter and to a lesser extent spring yield acceptable results. In contrast summer precipitation is poorly estimated from either fitting period. Summer, however, is characterized by a high quantity of convective showers which are not as closely related to large-scale circulation as advective precipitation. An example of the historical development and reconstruction of precipitation sums is illustrated in Fig. 4 for winter with Analog 1, demonstrating the per-

Table 1. Time series correlation coefficients $(r)$ between observation and reconstruction of precipitation in Cortina

\begin{tabular}{|lrrrr|}
\hline & MAM & JJA & SON & DJ F \\
\hline Analog 1 (1922-61) & & & & \\
Precipitation totals & 0.33 & 0.02 & 0.42 & 0.52 \\
Number of days $>0.2 \mathrm{~mm}$ & 0.24 & 0.04 & 0.45 & 0.47 \\
Intraseasonal variability & 0.32 & 0.00 & 0.30 & 0.40 \\
Analog 2 (1922-44 and & $\mathbf{1 9 7 6 - 9 4 )}$ & & & \\
Precipitation totals & 0.21 & -0.25 & 0.48 & 0.48 \\
Number of days >0.2 mm & 0.47 & 0.23 & 0.31 & 0.42 \\
Intraseasonal variability & 0.12 & -0.26 & 0.42 & 0.43 \\
\hline
\end{tabular}

Table 2. Validation of $\mathrm{q}_{0.9}$ (in $\mathrm{mm}$ ) and low-frequency variability of precipitation in Cortina for both analog model settings

\begin{tabular}{|c|c|c|c|c|}
\hline \multicolumn{3}{|c|}{$\begin{array}{c}\text { Analog } 1 \\
\text { Observation Estimation } \\
(1922-1961)\end{array}$} & \multicolumn{2}{|c|}{$\begin{array}{l}\text { Analog } 2 \\
\text { Observation Estimation } \\
(1922-1944 \text { and 1976-1994) }\end{array}$} \\
\hline $\begin{array}{l}q_{0.9} \\
\text { MAM }\end{array}$ & 21.0 & 16.0 & 21.1 & 18.6 \\
\hline J A & 20.0 & 17.4 & 20.6 & 17.8 \\
\hline SON & 31.0 & 22.8 & 28.8 & 26.6 \\
\hline DJ F & 19.5 & 16.0 & 18.2 & 26.1 \\
\hline \multicolumn{5}{|c|}{ Low-frequency variability } \\
\hline MAM & 98.7 & 97.0 & 104.3 & 89.3 \\
\hline JJA & 83.0 & 80.7 & 89.0 & 89.2 \\
\hline SON & 140.6 & 95.1 & 147.6 & 97.4 \\
\hline DJ F & 123.6 & 82.8 & 87.7 & 88.0 \\
\hline
\end{tabular}




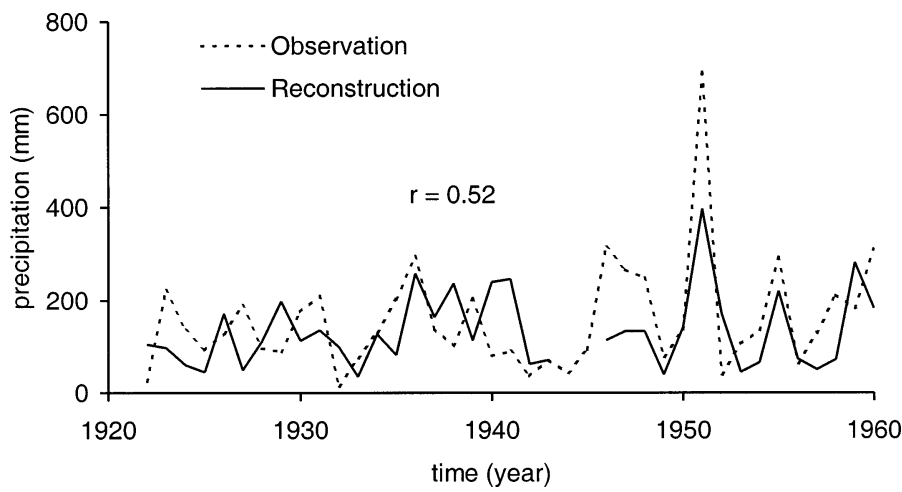

Fig. 4. Measured and reconstructed winter precipitation in Cortina, 1922-60. Reconstruction is based on the analog technique with the fitting period of Analog 1. Years 1944-46 are missing from the reconstruction due to missing SLP data in this period

formance of the technique. In summary, it could be shown that the analog technique based on SLP is able to successfully reconstruct the historical development of precipitation in Cortina in winter, spring and autumn, while average precipitation, maxima, and lowfrequency variability are generally underestimated. Furthermore the downscaling model seems not to be affected by non-stationarity. Despite some deficiencies the validation demonstrated the skill of the analog technique and therefore it was used for downscaling large-scale circulation features of GCM experiments.

\section{LOCAL CLIMATE CHANGE SCENARIOS}

\subsection{Local precipitation}

Future local precipitation scenarios for Cortina were developed with the analog technique based on SLP simulated in GCMs. In order to assess the uncertainty from different climate models 2 transient GCM experiments were used. The second generation Hadley Centre Coupled Model (HadCM2) with sulphate aerosols (J ohns et al. 1997) and the fourth generation European Centre Hamburg Model (ECHAM4) globally coupled with the ocean circulation model OPYC 3 without consideration of sulphate aerosols (Roeckner et al. 1996) have been selected. Both anomaly experiments are based on the emission scenario IS92a of the Intergovernmental Panel on Climate Change (IPCC) (Houghton et al. 1992). Horizontal resolution of $\mathrm{HadCM} 2$ is $2.5^{\circ} \times 3.75^{\circ}$ and of ECHAM 4/OPYC 3 approximately $2.8^{\circ} \times 2.8^{\circ}$. Further details can be found in the cited references. Due to the large amount of data in daily approaches only two $30 \mathrm{yr}$ periods of each GCM were used for downscaling purposes. The first period represents the present climate with observed greenhouse gas concentrations and is called 'control'. It covers the years 1960-89 of ECHAM 4/ OPYC3 and 1950-79 of HadCM 2. The use of differing control periods is due to technical and logistic problems of deriving daily GCM data. The files covering years 1980-89 of HadCM 2 were empty and data acquisition for years 1960-89 of ECHAM 4/OPYC 3 was already in process. The second period of both GCM s covers the years 2070-99 and represents climate change due to increasing greenhouse gas concentrations. Together with the 2 fitting periods there exist 4 scenarios of future local precipitation, that is Analog 1 and Analog 2 based on ECHAM 4/ OPYC3 and on HadCM2, respectively.

Results of analog downscaling of local precipitation are presented in Table 3 for the 2 GCM experiments and 2 fitting periods: again results are given for seasons. Only statistics of the $30 \mathrm{yr}$ periods are considered, because single weather events are not meaningful according to characteristics of climate modelling in GCMs (Trenberth 1997). Therefore the comparison is carried out on mean values of the precipitation totals, variability, and days with precipitation. Additionally values of $\mathrm{q}_{0.9}$ and low-frequency variability of the periods are considered. Local precipitation obtained with the analog technique from ECHAM 4/OPYC3 is decreased in SON with both fitting periods and with regard to all 5 parameters (significant at the $95 \%$ confidence level for precipitation sums). Precipitation amounts for example decrease by $19.9 \%$ and $27.5 \%$, respectively. For the other seasons changes are not significant. In the scenarios obtained with HadCM2 no season with significant changes of both analog models is visible such as SON with ECHAM 4/OPYC3. In contrast to the generally decreasing precipitation amounts with ECHAM 4/OPYC 3 there is a significant precipitation increase with HadCM 2 in DJ F with Analog $1(+33 \%)$ and in J A with Analog $2(+11 \%)$. Summer, however, was not succesfully validated as shown above. Therefore no further statements will be made for this season. Differences between estimations based on the same GCM but different fitting periods can be seen for both GCMs. Sometimes even changes of opposite sign occur, as, for example, between precipitation sums of SON with HadCM 2 or of MAM with ECHAM 4/OPYC3. These changes with opposite signs, however, are in no case significant on the $95 \%$ confidence level.

The scenarios based on ECHAM 4/OPYC 3 show a decreasing frequency of intense precipitation events as indicated by lowered $\mathrm{q}_{0.9}$, except for M AM with Analog 1 . The analog technique with $\mathrm{HadCM} 2$ and both fitting periods on the other hand is characterized by increased high intensity precipitation in winter and with A nalog 2 
Table 3. Percentage change of 5 precipitation parameters in Cortina between control (1960-89 with ECHAM 4/OPYC3 and 1950-79 with HadCM 2, respectively) and years 2070-99 of the GCM experiments. Bold values indicate significant changes at the $95 \%$ confidence level. No significance was calculated for the low-frequency variability and quantiles

\begin{tabular}{|c|c|c|c|c|}
\hline & $\mathrm{ECH}$ & PYC3 & HadCN & ulphate \\
\hline & Analog 1 & Analog 2 & Analog 1 & Analog 2 \\
\hline Precip & & & & \\
\hline MAM & -4.1 & +4.3 & -14.5 & -1.7 \\
\hline JJA & -6.7 & -3.0 & +5.3 & +10.7 \\
\hline SON & -19.9 & -27.5 & -2.5 & +7.2 \\
\hline DJ F & -13.7 & -14.2 & +33.2 & +8.7 \\
\hline Intras & & & & \\
\hline MAM & -0.4 & +10.7 & -16.8 & -7.2 \\
\hline J $A$ & -7.5 & +12.3 & +7.5 & +11.3 \\
\hline SON & -16.1 & -21.6 & -4.4 & +4.6 \\
\hline DJ F & -11.9 & -10.9 & +27.0 & +5.4 \\
\hline N umb & & & & \\
\hline MAM & -5.7 & +4.5 & -0.9 & +2.1 \\
\hline JJA & +3.6 & +1.7 & -1.7 & 0.0 \\
\hline SON & -11.9 & -7.4 & -2.4 & 0.0 \\
\hline DJ F & -8.5 & -4.3 & +2.0 & -5.0 \\
\hline Low-f & & & & \\
\hline MAM & -5.7 & +20.8 & -24.6 & +1.0 \\
\hline J $A$ & -18.9 & -10.3 & -4.7 & +29.5 \\
\hline SON & -33.2 & -28.8 & -13.1 & +65.1 \\
\hline DJ F & +17.8 & -25.7 & +45.8 & +39.5 \\
\hline$q_{0.9}$ of & & & & \\
\hline MAM & 0.0 & -4.5 & -10.5 & -3.7 \\
\hline JJA & -7.6 & -2.1 & +7.0 & +8.0 \\
\hline SON & -15.9 & -26.3 & -2.1 & +3.0 \\
\hline DJ F & -6.1 & -10.0 & +59.4 & +19.1 \\
\hline
\end{tabular}

also in SON. For A nalog 2 and HadCM 2 there is also a large increase in low-frequency variability $(+65.1 \%$ and $+39.5 \%)$ in SON and DJ F despite only small increases in precipitation totals $(+7.2 \%$ and $+8.7 \%)$. A similar pattern can be seen for ECHAM 4/OPYC3 with Analog 1 where a reduction in precipitation amounts $(-13.7 \%)$ is associated with an increase in low-frequency variability $(+17.8 \%)$. This indicates stronger year-to-year variations regarding seasonal precipitation amounts. Table 3 in general shows greater differences between the 2 GCM experiments than between the 2 analog models trained with different fitting periods.

\subsection{Local temperature}

In contrast to precipitation, the local temperature of Cortina was not derived by downscaling but by taking 1 single GCM grid point next to Cortina from either ECHAM 4/OPYC 3 or HadCM 2. Since air temperature does not show the same high spatial variability as precipitation it is supposed that this approach is justifiable. The annual cycles of temperature of GCM data and observations are shown in Fig. 5 and demonstrate the applicability of directly using GCM air tempera- ture data. It also shows differences between the use of 1 grid point and the average of several grid points next to Cortina. Differences of yearly average temperature between observations and GCM data are $0.9^{\circ} \mathrm{C}$ for 1 ECHAM 4 grid, $2.7^{\circ} \mathrm{C}$ for the average of $16 \mathrm{ECHAM} 4$ grids, $-4.7^{\circ} \mathrm{C}$ for $1 \mathrm{HadCM} 2$ grid, and $5.9^{\circ} \mathrm{C}$ for the average of $6 \mathrm{HadCM} 2$ grids. The single grid method is closer to observations than using the average of several grid points. This is due to the location of adjacent GCM grid points outside the model Alps and locations even in the Mediterranean Sea. For HadCM 2 the use of more grid points presents an annual cycle with reduced amplitude and smaller temperature increases (not shown) which could be an effect of grid point locations in the sea. Further, year-to-year variability of mean temperature of the average of several grid points is underestimated by about $60 \%$ for HadCM2. Lowfrequency variability of 1 grid point is only underestimated by about $10 \%$ for both GCMs.

The grid point values have to be calibrated taking into account the differences in the longterm mean obvious from Fig. 5. Based on the period 1955-85 values were fitted to local observations as follows:

correction_constant $\mathrm{i}_{\mathrm{i}}=\mathrm{T}_{\mathrm{i}}$ (observed) $-\mathrm{T}_{\mathrm{i}}$ (control) 
with $\mathrm{T}$ being the longterm mean monthly temperature of month $i=1,2, \ldots, 12$. These correction constants were used to calibrate the daily temperature scenarios. Fig. 6 shows the calibrated local temperature scenarios (based on monthly GCM data). As expected it is clear that the temperature rise in HadCM 2 (with consideration of sulphate aerosols) is smaller than in ECHAM 4/OPYC3 (without sulphate aerosols) (Mitchell et al. 1995). The average temperature increase between the control period and years 2070-99 is $+4.7^{\circ} \mathrm{C}$ for ECHAM 4/OPYC 3 and $+3.5^{\circ} \mathrm{C}$ for $\mathrm{HadCM} 2$.

\section{IMPACT SCENARIOS}

In this section the effects of these local precipitation and temperature scenarios on activity of Alvera mudslide, obtained by the approach given in Fig. 1, are considered. As with the climate scenarios, only mean states of the examined periods are used in the assessment. As explained before, the number of days with supercritical groundwater level has been taken as an indicator of landslide activity. In Fig. 7 the resulting scenarios of future landslide activity are presented. As in the case of local precipitation 4 different scenarios have been developed, given by the 2 GCM experiments and the 2 fitting periods.

In spring (MAM) there is a decrease in landslide activity, significant at the $95 \%$ confidence level, with both GCM experiments and both fitting periods. There is also a general decrease in activity in SON, which is significant with ECHAM 4/OPYC3. For the other seasons,

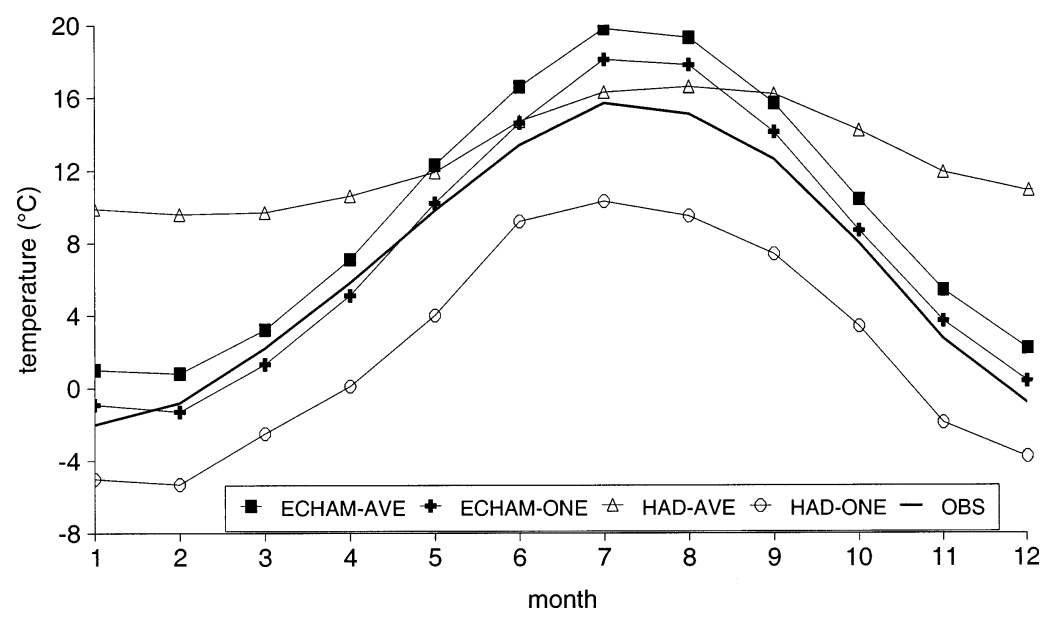

Fig. 5. Mean annual cycle of air temperature in Cortina, 1955-85. OBS = observed; ECHAM-AVE = average of 16 grid points of ECHAM 4; ECHAM ONE = one grid point of ECHAM 4; HAD-AVE = average of 6 grid points of $\mathrm{HadCM} 2$; HAD-ONE = one grid point of $\mathrm{HadCM} 2$ however, there is no uniform pattern of change obtained with the method described. With ECHAM 4/ OPYC 3 a general decrease of activity is simulated, which is most pronounced in spring. In one case there al so occurs a significant increase of landslide activity in winter based on $\mathrm{HadCM} 2$ with Analog 1, which is consistent with the $+33 \%$ precipitation change for that season. Except for MAM there is no similar pattern between the scenarios based on the 2 GCM experiments.

\section{DISCUSSION}

The scenarios of future landslide activity of Alvera mudslide are based on local scenarios of precipitation and temperature. This discussion focuses upon the signs of change, their statistical significance, and similarities between the 4 scenarios developed.

As described in Section 4.1 and presented in Table 3, there is noticeable scatter of the 4 different estimates of local precipitation. The differences between GCM experiments are considerable. There is no similar pattern between ECHAM 4/OPYC 3 and HadCM 2 with respect to the sign of change or seasons with significant changes. While generally decreasing precipitation amounts were found with ECHAM 4/OPYC3, there are some seasons with an increase in precipitation with HadCM 2. Furthermore, the precipitation scenarios developed with different fitting periods in some cases show changes with opposite signs. The latter finding calls in question the postulated stationarity of the downscaling model and should be addressed in further studies with the analog technique. 


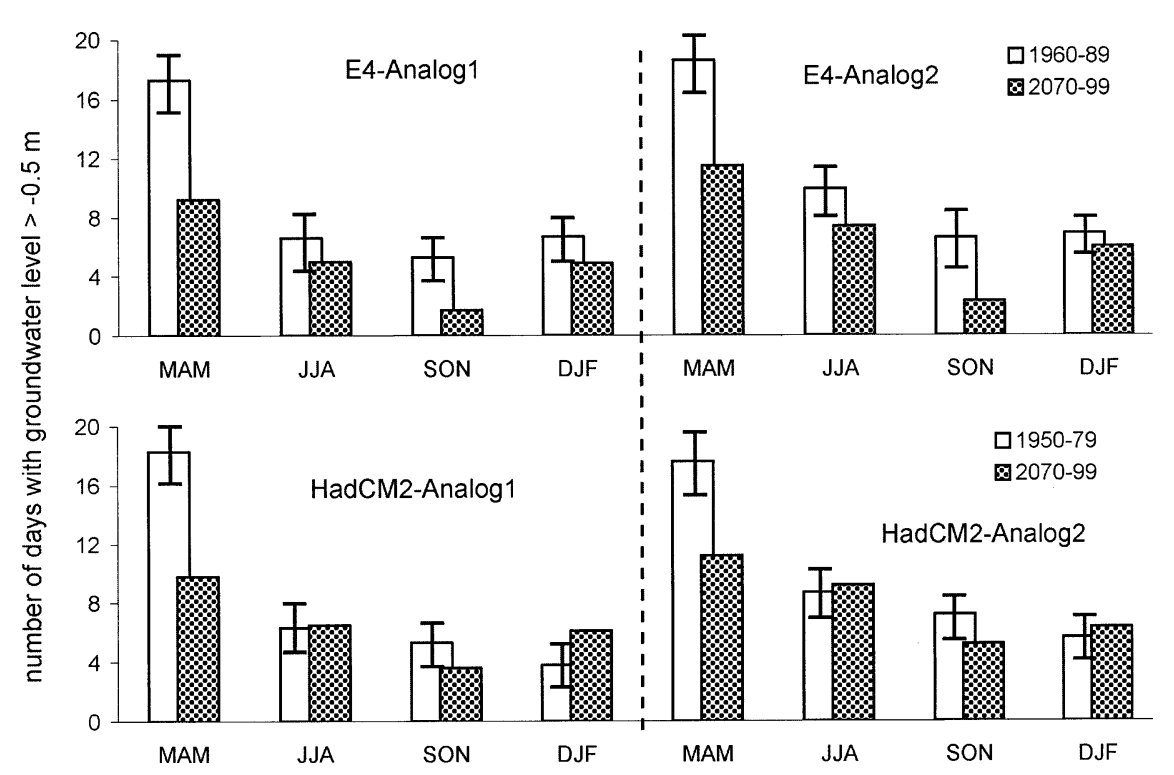

Fig. 7. Seasonal scenarios of landslide activity showing mean of control period with $95 \%$ confidence levels and mean of climate change period. Scenarios are based on 2 GCM experiments and the 2 fitting periods, Analog 1 and Analog 2. E4 =ECHAM 4/OPY C3s

The unequal signs of change, however, are in no case significant at the $95 \%$ confidence level. The uncertainty introduced by the inter-GCM differences is greater than the differences due to different fitting periods. Therefore it is absolutely necessary to use several GCM experiments for the construction of local climate change scenarios in order to derive a range of possible future situations. The study of Martin et al. (1997) with an analog technique for the French Alps also showed quite remarkable differences in precipitation scenarios based on different GCM experiments.

Local temperature scenarios show for both GCMs a significant temperature rise but with different gradients. The difference in this case is due to the consideration of sulphate aerosols in $\mathrm{HadCM} 2$ with its regional cooling effect and also varying model physics and model designs. It was demonstrated that the long-term mean annual cycle of temperature of $1 \mathrm{GCM}$ grid point next to the study area is close to the observed cycle for both GCMs. Therefore, it is argued that the calibration of the GCM data to fit observations is sufficient for the assessment of future landslide activity.

The scenarios of activity of Alvera mudslide induced by various precipitation and temperature changes show several features. In agreement with the precipitation changes there is a general decrease of activity simulated with ECHAM 4/OPYC3. Simulations based on HadCM 2 on the other hand show increasing activity in JJA and DJF. The most interesting feature is obvious in spring, with significant decreases of landslide activity for both GCM experiments and both fitting periods, respectively. There is no parallel to this finding in the other seasons. If precipitation were to be the cause of this result it should be reflected in the precipitation scenarios for spring. The respective precipitation scenario based on $\mathrm{HadCM} 2$ with Analog 1 is characterized by significantly decreasing precipitation of $-15 \%$. The other 3 precipitation scenarios for spring change only by about $\pm 5 \%$. Hence, it still has to be explained why a general and significant decrease of landslide activity in spring occurs which seems not to be caused by the simultaneous precipitation changes. The reason has to be sought in the strong temperature increase which is significant in all cases. An explanatory model is the role of snow storage of $D J F$ precipitation at present $D J F$ temperatures which contributes to high meltwater inputs into the slope system in early spring and hence triggers activity of Alvera mudslide. Global warming due to the enhanced greenhouse effect forces mean $D J F$ temperatures in Cortina of currently $-1.1^{\circ} \mathrm{C}$ to exceed $0^{\circ} \mathrm{C}$ in the middle of next century according to the GCM experiments with and without consideration of the cooling effect of sulphate aerosols (Fig. 6). This local warming reduces and finally removes the potential of snow storage in winter. In a warmer climate, therefore, less water is available for the slope in spring, with the consequence of lower groundwater levels and less landslide activity. In other words, the hydrograph of the currently high melt water supply in early spring is flattened with increasing winter temperatures. Thus the water supply is less concentrated in time and fewer days with supercritical groundwater conditions occur. Increasing evapotranspiration further enforces the decrease of activity. 
Again, it has to be noted that the applied hydrological model works with a fixed value of evapotranspiration of $2.5 \mathrm{~mm} \mathrm{~d}^{-1}$ for days with mean temperature above $9^{\circ} \mathrm{C}$. Therefore the effect of rising temperatures on evapotranspiration is not simulated realistically. While the threshold of $9^{\circ} \mathrm{C}$ does not affect J I A (nearly all days warmer) and DJ F (nearly all days colder) it does have an effect for MAM and SON. This shortcoming of the modelling of evapotranspiration does not put the sign of change into doubt, however, but only the accurate quantity of landslide activity. For the purpose of this paper this error is acceptable.

In order to test the proposed explanation for the strong reduction of landslide activity in spring the impact model was forced with different precipitationtemperature combinations. First only precipitation was changed for years 2070-99 while temperature was held unchanged as in the control period. Then the opposite situation was simulated, with unchanged precipitation and rising temperatures. This procedure was carried out for both GCMs and fitting periods, and hence 8 scenarios (Table 4). For spring there is no case of significant change with only changed precipitation and unchanged temperature, whereas for the reverse model design forced solely by the temperature increase there are significant reductions of activity in all cases. For the other seasons the temperature influence is not that important. In SON both temperature and precipitation changes cause significant changes with ECHAM 4/OPYC3. Based on HadCM 2 significant changes occur only with the temperature increase. In DJ $F$ it is only precipitation changes which cause significant changes of landslide activity. These findings support the suspected dominant influence of rising temperature as explanation for the decreasing landslide activity in spring.

Despite various sources of uncertainty and the use of different GCM experiments and fitting periods, the reduction of snow storage with the consequence of lowered landslide activity in spring arises as the main climate change signal. Therefore a higher confidence level can be assigned to this partial result compared to the other seasons. This finding is further confirmed by a climate change impact assessment obtained with an alternative downscaling technique known as expanded downscaling (Bürger 1996). Based on the ECHAM 4/OPYC3 experiment with consideration of sulphate aerosols this study also revealed the only significant change of landslide activity in spring, with a strong decrease (Dehn et al. 1998). However, there still exist other sources of uncertainty omitted in the construction of the scenarios. Boundary conditions of the mudslide, e.g. vegetation, slope morphology and material availability, are implicitly set constant in the scenarios, but they are also in part directly dependent on
Table 4. Sensitivity of landslide activity to changes in precipitation (P) or temperature ( $\mathrm{T}$ ) of the period 2070-99 in comparison to the respective control period of the GCMs. Values are mean number of days per season with critical groundwater levels. Bold values indicate significant changes at the $95 \%$ confidence level

\begin{tabular}{|lrrrr|}
\hline & MAM & JJA & SON & DJ F \\
\hline ECHA M 4/O PYC 3 & & & & \\
Analog 1 & & & & \\
Control, 1960-89 & 17.3 & 6.6 & 5.3 & 6.8 \\
Only P changing, 2070-99 & 15.8 & 5.9 & $\mathbf{3 . 3}$ & $\mathbf{4 . 3}$ \\
Only T changing, 2070-99 & $\mathbf{9 . 5}$ & 6.0 & $\mathbf{3 . 7}$ & 6.8 \\
Analog 2 & & & & \\
Control, 1960-89 & 18.6 & 9.9 & 6.6 & 7.0 \\
Only P changing, 2070-99 & 18.3 & 8.3 & $\mathbf{3 . 8}$ & $\mathbf{5 . 1}$ \\
Only T changing, 2070-99 & $\mathbf{1 0 . 7}$ & 9.3 & $\mathbf{4 . 2}$ & 7.3 \\
H adC M 2 & & & & \\
Analog 1 & & & & \\
Control, 1950-79 & 18.3 & 6.3 & 5.3 & 3.8 \\
Only P changing, 2070-99 & 16.9 & 7.1 & 5.5 & $\mathbf{5 . 6}$ \\
Only T changing, 2070-99 & $\mathbf{1 2 . 0}$ & 5.9 & 3.4 & 4.3 \\
Analog 2 & & & & \\
Control, 1950-79 & 17.6 & 8.7 & 7.2 & 5.6 \\
Only P changing, 2070-99 & 17.8 & 9.9 & 7.4 & 5.3 \\
Only T changing, 2070-99 & $\mathbf{1 0 . 2}$ & 8.1 & $\mathbf{4 . 7}$ & 6.4 \\
\hline
\end{tabular}

climate change, as in the case of vegetation. Slope morphology and material availability might change significantly in the course of time due to the downward movement of the mudslide creating new conditions for slope hydrology and stability. A complete impact assessment therefore would have to take into account all of these boundary conditions of slope behaviour, in addition to precipitation and temperature changes.

The scenarios are site specific with regard to the slope system and climatic environment of Alvera and should not be transferred to other types of landslides or other locations in the Alps without further research. Future studies will compare the behaviour of the Alvera mudslide and scenarios of the Boisivre landslide in the French Alps, which is described in Buma \& Dehn (in press) and Dehn \& Buma (1999).

Finally, it should be noted that despite the differences between the GCM s both are based on the emission scenario IS92a, which also contains considerable sources of uncertainty (Houghton et al. 1996). This uncertainty could not be assessed since long GCM experiments are normally integrated with 1 emission scenario only.

\section{CONCLUSIONS}

The applied model chain for the assessment of landslide activity of the Alvera mudslide permits estimation 
of climate change impacts induced by the enhanced greenhouse effect. The following conclusions can be drawn from the study:

- The analog technique trained with 2 different fitting periods and applied to $2 \mathrm{GCM}$ experiments returns different trends of changing precipitation. This scatter can be treated as uncertainty inherent to the method. Between-GCM differences are more important than differences between fitting periods.

- Temperature is derived from GCM experiments directly with an acceptable degree of accuracy. M onthly corrections are needed to adapt the scenarios to local conditions.

- The general decrease of landslide activity in spring simulated with 4 local climate scenarios points to the importance of mean winter temperature as one key parameter of this landslide system. This effect is so dominant that despite uncertainties in the precipitation scenarios it determines the main climate change impact in all cases. For the other seasons no uniform and clear climate change signal could be distinguished.

- The results suggest that the use of various GCM experiments and fitting periods for the downscaling approach is proper for a preliminary assessment of uncertainties of local climate change impact assessments.

- An improvement of the described approach should consist of isolating the cause of the seeming instationarity in the downscaling model for precipitation, an improved derivation of local temperature, an evaluation of the ability of the hydrological model to represent snow storage and snow melt, and the development of a more sophisticated temperaturedependent evapotranspiration term in the hydrological model.

- A complete assessment of local climate change impacts would require the use of even more than 2 GCMs, the use of different downscaling techniques, and the quantification of the effect of changing local boundary conditions, e.g. vegetation, slope morphology and material availability.

- The scenarios of landslide activity are site specific for Alvera and should not be taken as reliable for any other landslide in the Alps.

Acknowledgements. This paper is part of the CEC Environment Research Programme on 'New technologies for landslide hazard assessment and management in Europe (NEWTECH)' (ENV4-CT96-0248). I would like to thank Eduardo Zorita and Hans von Storch, GKSS Research Center, Geesthacht, for assistance and cooperation with the analog technique, J elle Buma, University of Utrecht, for the use of the hydrological model which he developed and discussion of the results, and Erich Roeckner and M onika Esch from the MaxPlanck-Institut für M eteorologie, Hamburg, and David Viner from Climate Impacts LINK project, Norwich, for providing GCM data. Finally, the comments and suggestions of 3 reviewers are gratefully acknowledged.

\section{LITERATURE CITED}

Angeli MG, Buma J , Gasparetto P, Pasuto A, Silvano S (1998) A combined hillslope hydrology/stability model for lowgradient clay slopes in the Italian Dolomites. Eng Geol 49: 1-13

Angeli MG, Gasparetto P, Menotti RM, Pasuto A, Silvano S (1996) A visco-plastic model for slope analysis applied to a mudslide in Cortina d'Ampezzo, Italy. Q J Eng Geol 29: 233-240

Bergström S (1976) Development and application of a conceptual runoff model for Scandinavian catchments. Swedish Meteorology and Hydrology Institute Rep RHO, no. 7, Norrköping

Buma J (1998) Modelling the impact of climate change on a landslide in the Italian Dolomites. Netherlands Centre for Geo-ecological Research Report, 98/5, Amsterdam

Buma J , Dehn M (1998) A method for predicting the impact of climate change on slope stability. Environ Geol 35: 190-196

Buma J , Dehn M (in press) The impact of climate change on a landslide in South East France, simulated using different GCM-scenarios and downscaling methods for local precipitation. Clim Res

Bürger G (1996) Expanded downscaling for generating local weather scenarios. Clim Res 7:111-128

Carter T, Parry M, Nishioka S, Harasawa H (1996) Technical guidelines for assessing climate change impacts and adaptations. In: Watson RT, Zinyowera M C, M oss RH, Dokken DJ (eds) Climate change 1995. Impacts, adaptations and mitigation of climate change: scientific-technical analysis. Cambridge University Press, Cambridge, p 823-833

Crowe PR (1971) Concepts in climatology. Longman, London

Crozier M (1986) Landslides: causes, consequences and environment. Croom Helm, London

Cubasch U, von Storch H, Waszkewitz J , Zorita E (1996) Estimates of climate change in Southern Europe derived from dynamical climate model output. Clim Res 7:129-149

Dehn M, Buma J (1999) Modelling future landslide activity based on general circulation models. Geomorphology 30: (in press)

Dehn M , Bürger G, Buma J , Gasparetto P (1998) Impact of climate change on slope stability using expanded downscaling. Eng Geol (in press)

Dikau R, Brunsden D, Schrott L, Ibsen ML (eds) (1996) Landslide recognition. Identification, movement and causes. Wiley \& Sons, Chichester

Gasparetto P, M osselman M, van Asch TWJ (1996) The mobility of the Alvera landslide (Cortina d'Ampezzo, Italy). Geomorphology 15:327-335

Gostelow TP (1991) Rainfall and landslides. In: Almeida-Teixeira ME, Fantechi R, Oliveira R, Gomes Coelho A (eds) Prevention and control of landslides and other mass movements. Commission of the European Community, Brussels, p 139-161

Hewitson BC, Crane RG (1996) Climate downscaling: techniques and application. Clim Res 7:85-95

Houghton JT, Callander BA, Varney SK (eds) (1992) Climate change 1992. The supplementary report to the IPCC scientific assessment. Cambridge University Press, Cambridge 
Houghton J T, M eira Filho LG, Callander BA, Harris N, Kattenberg A, Maskell K (eds) (1996) IPCC climate change 1995. Cambridge University Press, Cambridge

J ohns TC, Carnell RE, Crossley J F, Gregory J M, M itchell J FB, Senior CA, Tett SFB, Wood RA (1997) The Second Hadley Centre coupled ocean-atmosphere GCM : model description, spinup and validation. Clim Dyn 13:103-134

Martin E, Timbal B, Brun E (1997) Downscaling of general circulation model outputs: simulation of the snow climatology of the French Alps and sensitivity to climate change. Clim Dyn 13:45-56

Mitchell J FB, J ohns TC, Gregory J M, Tett S (1995) Climate response to increasing levels of greenhouse gases and sulphate aerosols. Nature 376:501-504

Editorial responsibility: Hans von Storch, Geesthacht, Germany
Roeckner E, Oberhuber J M, Bacher A, Christoph M, Kirchner I (1996) ENSO variability and atmospheric response in a global coupled atmosphere-ocean GCM. Clim Dyn 12: 737-754

Trenberth KE (1997) The use and abuse of climate models. Nature 386:131-133

Trenberth KE, Paolino DA (1980) The Northern Hemisphere sea-level pressure data set: trends, errors, and discontinuities. M on Weather Rev 108:855-872

von Storch H (1995) Inconsistencies at the interface of climate impact studies and global climate research. Meteorologische ZNF 4:72-80

Zorita E, von Storch H (1998) A survey of statistical downscaling techniques. GKSS Report 97/E/20, Geesthacht

Submitted: J anuary 26, 1999; Accepted: J une 9, 1999

Proofs received from author(s): September 2, 1999 